www.jmscr.igmpublication.org

Index Copernicus Value: 79.54

ISSN (e)-2347-176x ISSN (p) 2455-0450

crossref DOI: https://dx.doi.org/10.18535/jmscr/v7i6.171

Journal Of Medical Science And Clinical Research

IGM Publication

An Official Publication of IGM Publication

\title{
Pulmonary Artery Hypertension and HIV; A tertiary care centre based comparative analysis
}

\author{
Authors \\ Dr Vinay Tuteja ${ }^{1}$, Dr C.L.Nawal ${ }^{2}$, Dr Aradhana Singh ${ }^{3}$, Dr R.S. Chejara ${ }^{4}$, \\ Dr Pradeep Kumar Bansal ${ }^{\text {** }}$ \\ ${ }^{1,5}$ Resident, ${ }^{2}$ Sr.Professor, ${ }^{3,4}$ Associate Professor \\ *Corresponding Author \\ Pardeep Kumar Bansal \\ SMS Medical College, Jaipur, India
}

\section{Abstract}

Introduction: HIV is a secondary immunodeficiency disease state characterized by fairly raised incidence of multiple systemic and cutaneous conditions, leading to increased morbidity and mortality. Advent of HAART has changed the natural course of the disease and many non-infective diseases have been unfolded in the patients of HIV, with cardiovascular diseases being at the top of the list. Pulmonary artery hypertension is also very frequently encountered in HIV infected patients.

Material and Methods: Total of 200 individuals including 100 patients of HIV and 100 controls were taken, study population was further divided into 3 groups on basis of duration of cART and then on the basis of CD4 count. After clinical assessment, chest x-ray, electrocardiogram and 2-dimensional echocardiography were done. Unpaired ' $t$ ' test was used for comparison of continuous variable; chi square test was used for qualitative data and ANOVA was used to analyze variance.

Observations and Results: Male to female ratio in cases and control was 3.3:1. Cases divided according to CD4 count and patients having CD4 <200/200-350/>350, the mean CD4 count was 108.47 $\pm 36.51 / 277.85 \pm$ 46.73/576.63 \pm 195 respectively. Pulmonary artery hypertension (PAH) was found in $10 \%$ patients, also $3(30 \%)$ patients had moderate grade of $P A H$.

Conclusion: PAH due to HIV is an infrequent complication of the infection. The pathophysiology of HIVrelated PAH is complex and not fully understood. Early diagnosis and timely institution of PAH-specific therapies, can improve the life expectancy as well as quality of life in these patients.

Keywords: Human Immunodeficiency Virus, Pulmonary Artery Hypertension, CD4 count, Echocardiography.

Key Messages: With the advent of HAART, life of HIV infected patients has improved significantly, but with prolonged life comes many non-infective diseases due to various unknown factors, PAH is one such disease and it is very important to early recognize and treat the same. Echocardiography is an excellent non invasive tool for this purpose.

\section{Introduction}

Human immunodeficiency virus (HIV) is an infectious disease, which causes rapid fall in the body's immune system, thus making a way for life threatening opportunistic infections and cancers into the body. ${ }^{1}$ About 36.9 million people are 
living with HIV around the world right now and there were about 1.8 million new cases of HIV in $2017^{2}$. An estimated 35 million people have lost their lives from AIDS-related illnesses so far. Situation in INDIA is no different than rest of the word, during 2017, the new HIV infections reported were 88, 000 and HIV incidence per 1000 population was $0.1 .^{2}$

HIV infection confers an increased risk for a variety of infectious lung diseases, including bacterial pneumonia, tuberculosis, and other atypical pneumonia. HIV infection is an established risk factor for $\mathrm{PH}$. The prevalence of $\mathrm{PH}$ is several-fold higher in HIV-infected individuals compared with the general population $^{3}$. Patients with PAH, typically present with progressive dyspnoea and nonproductive cough. As the disease progresses, the signs of Right ventricular involvement becomes evident, patients may present with pedal edema, fatigue, distended neck veins, syncope and chest pain.

Pulmonary hypertension attributable to any secondary systemic illness is classified as group $1^{4}$ (Table 1). Chest X-Ray and chest CT scans may show prominent central pulmonary arteries and right ventricular and atrial enlargement may be seen. Pulmonary function tests may reveal a mild restrictive pattern with a decreased diffusing capacity for carbon monoxide.

Electrocardiogram findings include right ventricular hypertrophy, right axis deviation, RBBB, and right atrial enlargement. Echocardiograms may reveal enlargement of the right ventricular and atrial enlargment, decreased right ventricular systolic function, right ventricular hypertrophy and tricuspid regurgitation. Although Right Heart Catheterization is the gold standard diagnostic test for this condition, However echocardiogram can be used as a noninvasive modality to estimate Pulmonary Artery pressure and thus PAH. Which is defined as a mean pulmonary artery pressure more than $25 \mathrm{~mm} \mathrm{Hg}$ at rest, with a normal pulmonary capillary wedge pressure $(\leq 15 \mathrm{~mm} \mathrm{Hg}){ }^{5}$
The pathogenesis of HIV-related PAH is not completely understood. The pulmonary vasculature is susceptible to numerous complex events that may trigger pulmonary hypertension in a patient with HIV infection. The endothelium of the pulmonary vasculature is exposed to various blood components and to the extracellular matrix. The vascular involvement in HIV infection, in form of arteriopathy with smooth muscle hyperplasia in patients with AIDS can occur. ${ }^{6}$

\section{Material and Methods}

100 HIV infected patients of age $\geq 18$ years were included in this study. Clinical assessment, electrocardiography (ECG), chest radiography, and Doppler echocardiographic examination done. Haemoglobin measurement, CD4 count, ESR and routine serum biochemistry analysis was done. Patients with Hypertension, Type 2 DM, Ischemic heart disease and Cardiac involvement were excluded. 100, HIV-negative individuals served as controls. They were recruited after voluntary screening in the HIV clinic side laboratory to confirm their negative status. They were recruited to match the age and gender of the HIV cases.

Transthoracic echocardiography was performed. Two-dimensional (2D), M-mode, pulse-wave, continuous-wave and colour Doppler echocardiography assessment was done with the subject in the left lateral decubitus position. The two-dimensional images were obtained in the parasternal long and short-axis views, apical and subcostal views.

The MPAP was calculated from the initial peak velocity of the PR spectrum and adding the RA pressure to it. ${ }^{7}$

$$
\text { mPAP = 4(PR peak velocity }) 2+R A P,
$$

Right atrial pressure measured according to 2010 ASE guidelines $^{8}$ (Table 2) and the IVC collapsibility index was calculated using the formula

(maximum IVC diameter - minimum IVC diameter)/maximum IVC diameter 


\section{Results}

100 patients with HIV infection who were hospitalized and attending ART centre were studied. 100 healthy control subjects were recruited for the study. With Male to Female ratio was 3.3:1. Youngest subject among cases and control was 18 year old, while the oldest was 50 years old, with a mean age of $36.84( \pm 8.03)$ years in cases and $38.04( \pm 7.08)$ years in controls respectively $(\mathrm{p}=.264)$. The CD4 count ranged from 29 to $1112 / \mu$ with a mean of $247.04 \pm 211.4 / \mu 1 . C D 4$ count was less than $200 / \mu$ in $57 \%, 21 \%$ of cases had CD4 count between 200 to $350 / \mu 1$ and $22 \%$ had CD4 Count $<200 / \mu 1$.

10 patients had pulmonary artery hypertension, whereas no PAH was seen among controls, 3 patients had moderate grade PAH. In this study $41 \%$ individuals among cases had abnormal ECG findings in comparison to controls, whereas only $8 \%$ patients among these showed only minor arrhythmias. A significant negative correlation was observed between the mean PAP and CD4 count among cases $(r=-0.2653, p=0.007$ HS) by using Pearson's correlation coefficient. (Figure 1)Out of total patients with abnormal ECG findings $34 \%$ of patients had a CD4 count $<200$. The average CD4 count of patients with abnormal ECGs was 140.6 and average CD4 count of patients with normal ECG was 321. Among patients with $\mathrm{PAH}, 5$ patients had RBBB, 1 had Right Axis Deviation, 2 had Minor ST-T changes and 2 had a Normal ECG.

Table 1 Clinical Classification of Pulmonary Hypertension ${ }^{13}$

\begin{tabular}{|l|l|}
\hline Table 1: Classification of PH. & \multicolumn{1}{|c|}{ Etiologies } \\
\hline Group & $\begin{array}{l}\text { Idiopathic, heritable, connective tissue disease, Human } \\
\text { immunodeficiency virus infection, congenital heart } \\
\text { disease, drug/toxin induced, chronic hemolytic anemia, } \\
\text { schistosomiasis, persistent PH of the newborn, pulmonary } \\
\text { veno-occlusive disease and pulmonary capillary } \\
\text { hemangiomatosis. }\end{array}$ \\
\hline Group 2. PH owing to left heart disease & $\begin{array}{l}\text { Systolic and diastolic dysfunction, mitral and aortic valve } \\
\text { diseases. }\end{array}$ \\
\hline $\begin{array}{l}\text { Group 3. Pulmonary hypertension owing to lung } \\
\text { diseases and/or hypoxia }\end{array}$ & $\begin{array}{l}\text { Chronic obstructive pulmonary disease, interstitial lung } \\
\text { disease, sleep disordered breathing, and so forth. }\end{array}$ \\
\hline $\begin{array}{l}\text { Group 4. Chronic thromboembolic pulmonary } \\
\text { hypertension }\end{array}$ & $\begin{array}{l}\text { Unresolved fibrin thromboembolization to the pulmonary } \\
\text { arteries. }\end{array}$ \\
\hline $\begin{array}{l}\text { Group 5. Pulmonary hypertension with unclear } \\
\text { multifactorial mechanisms }\end{array}$ & $\begin{array}{l}\text { Myeloproliferative disorders, splenectomy, pulmonary } \\
\text { vasculitis, neurofibromatosis, thyroid disorders, and so } \\
\text { forth. }\end{array}$ \\
\hline
\end{tabular}

Table 22010 ASE guidelines to measure Right Atrial Pressure ${ }^{14}$

\begin{tabular}{|l|l|}
\hline 2010 ASE guidelines \\
\hline NORMAL & IVC maximum $\leq 2.1 \mathrm{~cm}$ and collapsibility index $>50 \%$ \\
\hline INTERMEDIATE & IVC maximum $\leq 2.1 \mathrm{~cm}$ and collapsibility index $<50 \%$ \\
\hline HIGH & IVC maximum $>2.1 \mathrm{~cm}$ and collapsibility index $<50 \%$ \\
\hline
\end{tabular}


Figure 1 Showing Correlation between CD4 counts and mean PAP

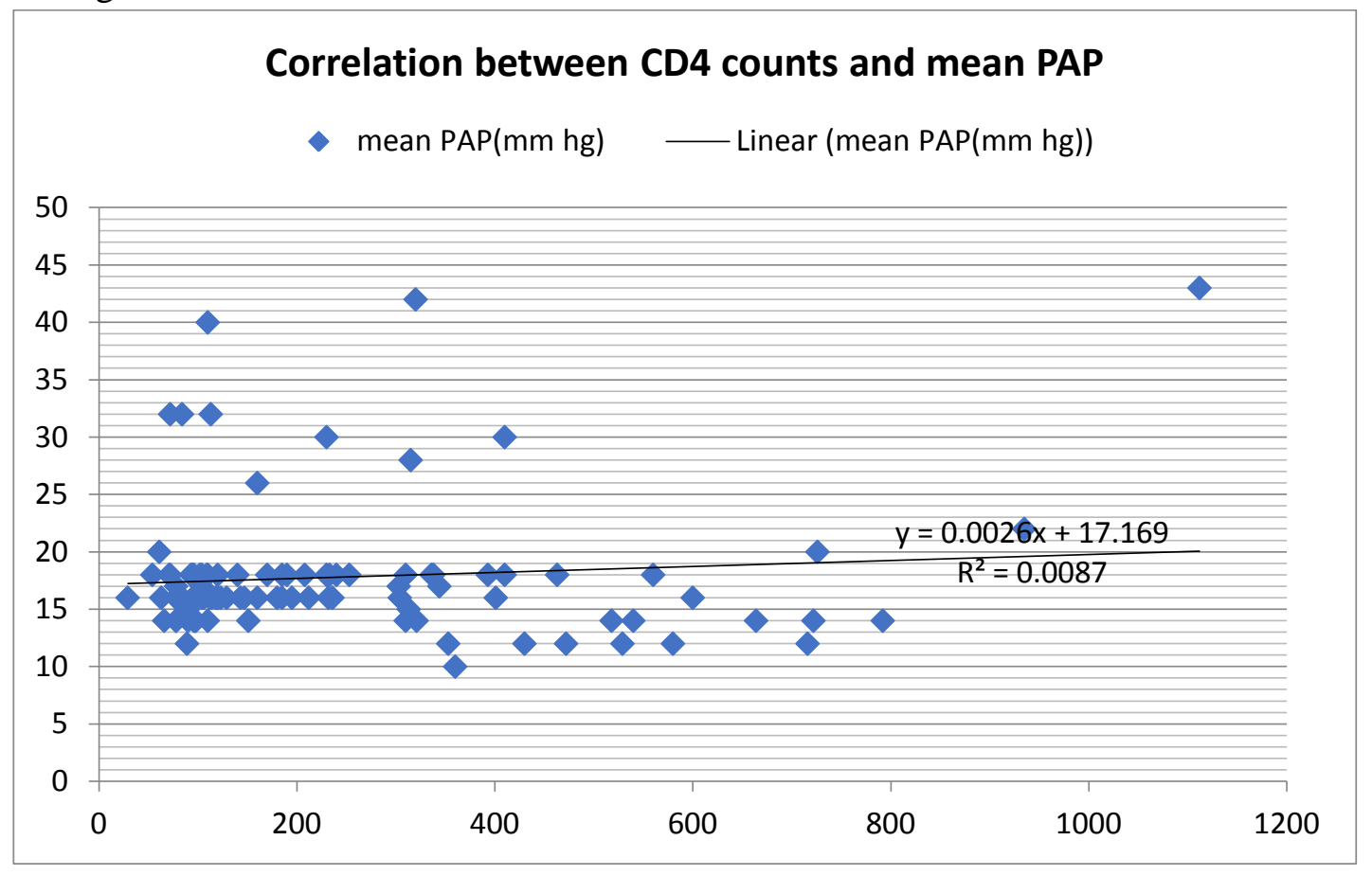

\section{Discussion}

The incidence of HIV-associated pulmonary hypertension is estimated to be $1 / 200$, whereas, in the general population it is much lower that is $1 / 200$ 000. ${ }^{9}$ Probable causes for pulmonary hypertension in HIV-infected patients can be Coinfections, thromboembolism and left ventricular systolic dysfunction. ${ }^{10}$

The method used to estimate PAH in our study may have many pitfalls, PR signal may be poor, parallel alignment of the Doppler signal may not be possible and in the presence of constrictive or restrictive $\mathrm{RV}$ physiology $\mathrm{PR}$ signal may be unreliable in the calculation of pulmonary artery pressure. $^{11}$ In constrictive physiology of right ventricle, there is a dissociation between intracardiac and intrathoracic pressures, leading to early equalisation of PA and RV pressures. This results in a short and steep PR signal. ${ }^{12}$

Primary pulmonary hypertension has been reported in HIV-infected patients without a history of thromboembolic disease, intravenous drug use, or pulmonary infections associated with HIV.

100 patients with HIV infection presented to indoor and registered in ART centre and 100 controls were included in this study. Majority of the patients, 77 patients were males and 23 patients were females. We further scrutinized cases according to CD4 count and thus observed that mean CD4 among the three groups that is, with CD4 count $<200 / 200-350 />350$ was $108.47 \pm$ $36.51 / 277.85 \pm 46.73 / 576.63 \pm 195.45$ and among patients with CD4 count $<200,84.21 \%$ were male and $15.78 \%$ were female.

10 patients among cases had evidence of PAH which was statistically significant with $p$ value of 0.002 , also among these, $3(30 \%)$ patients had moderate grade $\mathrm{PAH}$. PAH was observed in none of the controls. Similar observations were seen in study done by Maurya SK et $\mathrm{al}^{13}$, in which 16 $(14 \%)$ patients had pulmonary artery hypertension ( $\mathrm{p}=0.030)$, compared with controls.

However, our study failed to show any correlation of PAH and CD4 count and also with the duration of HAART as well. Similar findings were also observed in a study done by Klein D. et al. ${ }^{14}$

\section{Conclusion}

$\mathrm{PAH}$ due to HIV is rare complication of the infection. The mechanism behind the pathophysiology of HIV-related PAH is complex, with viral proteins likely to play the major role. However, various other factors, namely coinfection with other microorganisms and HIV- 
related systemic inflammation, might also contribute. The clinical presentation of HIVrelated PAH is similar to other forms of Pulmonary hypertension. Early institution of PAH-specific therapies, can improve the life expectancy as well as quality of life in these patients.

\section{References}

1. Vinay Kumar, MBBS, MD, FRCPath; Abul K. Abbas,MBBS; Nelson Fausto, MD; JON C. Aster, $\mathrm{MD}, \mathrm{PhD}$, Robbins and Cotran Pathologic Basis of Disease, Chapter6Diseases of the immune system, Elsevier, Philadelphia, Pennsylvania, 2010;183-254

2. Joint United Nations Programme on HIV/AIDS (UNAIDS) Opravil M, Sereni D. Natural history of HIV-associated pulmonary arterial hypertension: trends in the HAART era. AIDS2008;22:S35-S40. [PubMed] [Google Scholar]

3. Journal of the American College of Cardiology Vol. 62, No. 25. Suppl D. 2013

4. Badesch DB, Champion HC, Sanchez MA, Hoeper MM, Loyd JE, Manes A, McGoon M, Naeije R, Olschewski H, Oudiz RJ, et al.Diagnosis and assessment of pulmonary arterial hypertension. J Am Coll Cardiol2009;54:S55-S66.

5. Marecki JC, Cool CD, Parr JE, Beckey VE, Luciw PA, Tarantal AF, Carville A, Shannon RP, Cota-Gomez A, Tuder RM, et al. HIV-1 Nef is associated with complex pulmonary vascular lesions in SHIV-nefinfected macaques. Am J Respir Crit Care Med 2006;174:437-445. [PMC free article] [PubMed] [Google Scholar]

6. Abbas AE, Fortuin FD, Schiller NB, Appleton CP, Moreno CA,Lester SJ. Echocardiographic determination of mean pulmonary artery pressure. Am J Cardiol 2003;92:1373-6.

7. Lang RM, Bierig M, Devereux RB, et al. ; Chamber Quantification Writing Group;
American Society of Echocardiography's Guidelines and Standards Committee; European Association of Echocardiography. Recommendations for chamber quantification: a report from the American Society of Echocardiography's Guidelines and Standards Committee and the Chamber Quantification Writing Group, developed in conjunction with the European Association of Echocardiography, a branch of the European Society of Cardiology. J Am Soc Echocardiogr. 2005;18(12):14401463.

8. Rerkpattanapipat $\mathrm{P}$, Wongpraparut $\mathrm{N}$, Jacobs LE, Kotler MN. Cardiac manifestations of acquired immunodeficiency syndrome. Arch Intern Med 2000;160:602-8

9. Pellicelli A, Barbaro G, Palmieri F, et al. Primary pulmonary hypertension in HIV disease: a systematic review. Angiology 2001; 52: 31-41 [PubMed]

10. Kaga S., Mikami T., Takamatsu Y. Quantitative and pattern analyses of continuous-wave Doppler-derived pulmonary regurgitant flow velocity for the diagnosis of constrictive pericarditis. J. Am. Soc. Echocardiogr. 2014; 27(11): 12231229. [PubMed] [Google Scholar]

11. Gilman G., Ommen S.R., Hansen W.H. Doppler echocardiographic evaluation of pulmonary regurgitation facilitates the diagnosis of constrictive pericarditis. J. Am. Soc. Echocardiogr. 2005;18(9):892-895. [PubMed] [Google Scholar]

12. Maurya SK et al. Int J Adv Med. 2017 Jun;4(3):783-787

13. Klein D, Hurley LB, Quesenberry CP, Jr, Sidney S. Do protease inhibitors increase the risk for coronary heart disease in patients with HIV-1 infection. J Acquir Immune Defic Syndr. 2002 Aug 15; 30(5): 471-7. 